\title{
Characteristics of Cerebral Aneurysms in Japan
}

\author{
Fusao IKAWA, ${ }^{1}$ Toshikazu HIDAKA, ${ }^{1}$ Michitsura YoshIYAMA, ${ }^{1}$ Hideo OHBA, ${ }^{1}$ \\ Shingo MATSUdA, ${ }^{1}$ Iori OzONO, ${ }^{1}$ Koji IIHARA, ${ }^{2}$ Hiroyuki KinOUCHI, ${ }^{3}$ \\ Kazuhiko NOZAKI ${ }^{4}$ Yoko KATO, ${ }^{5}$ Akio MORITA, ${ }^{6}$ Nobuaki MiCHIHATA, ${ }^{7}$ \\ Hideo YASUNAGA, ${ }^{7}$ and Kaoru KURISU ${ }^{8}$
}

\author{
${ }^{1}$ Department of Neurosurgery, Shimane Prefectural Central Hospital, \\ Izumo, Shimane, Japan; \\ ${ }^{2}$ Department of Neurosurgery, Graduate School of Medical Sciences Kyushu \\ University, Fukuoka, Fukuoka, Japan; \\ ${ }^{3}$ Department of Neurosurgery, Faculty of Medicine, University of Yamanashi, \\ Chuo, Yamanashi, Japan; \\ ${ }^{4}$ Department of Neurosurgery, Shiga University of Medical Science, Otsu, Shiga, Japan; \\ ${ }^{5}$ Department of Neurosurgery, Fujita Health University Bantane Hospital, Nagoya, \\ Aichi, Japan; \\ ${ }^{6}$ Department of Neurological Surgery, Nippon Medical School Hospital, Tokyo, Japan; \\ ${ }^{7}$ Department of Clinical Epidemiology and Health Economics, School of Public Health, \\ The University of Tokyo, Tokyo, Japan; \\ ${ }^{8}$ Department of Neurosurgery, Graduate School of Biomedical and Health Sciences, \\ Hiroshima University, Hiroshima, Hiroshima, Japan
}

\begin{abstract}
The characteristics of cerebral aneurysms in Japan differ from other countries in the higher incidence of unruptured cerebral aneurysm detected by brain check-up screening, higher rupture rate of unruptured cerebral aneurysm, higher incidence of subarachnoid hemorrhage, and superior outcome after subarachnoid hemorrhage based on meta-analysis. Head shape, genetic features, environmental factors, demographics, and medical system in Japan are also different from other countries. Unruptured cerebral aneurysms are 2.8 times more likely to rupture in Japanese than western aneurysms, resulting in the highest incidence of subarachnoid hemorrhage in the world. The exact and specific mechanisms of de novo, growth, and rupture of cerebral aneurysms have not been elucidated. Investigations will contribute to the understanding of cerebral aneurysms and subarachnoid hemorrhage worldwide. Some features of cerebral aneurysm in Japan are discussed for possible research guidance in the elucidation of the predominance of subarachnoid hemorrhage in Japan.
\end{abstract}

Key words: cerebral aneurysm, subarachnoid hemorrhage, unruptured cerebral aneurysm, outcome

\section{Introduction}

Meta-analysis of mortality after subarachnoid hemorrhage (SAH) found $11.8 \%$ rates in Japan, lower than other countries. ${ }^{1)}$ More recent meta-analysis of complications, case-fatality, and risk factors of unruptured cerebral aneurysm (UCA) revealed that the risk was about half in Asia compared with other areas after endovascular treatment and about one-fifth

Received May 14, 2019; Accepted July 16, 2019

Copyright $@ 2019$ by The Japan Neurosurgical Society This work is licensed under a Creative Commons AttributionNonCommercial-NoDerivatives International License. after neurosurgical treatment. ${ }^{2)}$ Genetic characteristics, usual lifestyle, medical environment and resources, and the medical insurance system are different in Japan compared with other countries. Organization for Economic Co-operation and Development (OECD) health data shows that Japan has the most acute care beds per 1000 population, and the highest number of computed tomography (CT), magnetic resonance imaging per million population. ${ }^{3)}$ Additionally, the universal health care system has been totally controlled by the Government in Japan. Japan has more than 1000 neurosurgical facilities for patients with $\mathrm{SAH}$ to provide care, and 9688 neurosurgeons and 7685 board-certified neurosurgeons were available in 2017, 
so earlier diagnosis and more optimal treatment may be available in Japan. Consequently, emergent care for SAH is more easily accessible, and patients with SAH may be taken after earlier in Japan. The present review describes the characteristics and originality of cerebral aneurysm research in Japan.

\section{SAH Incidence Worldwide and Japan}

Finland ${ }^{4)}$ and Japan ${ }^{5)}$ have the highest incidences of SAH worldwide, but recent evidence does not support the abnormally high incidence of SAH in Finland. ${ }^{6)}$ The misconception of such an exceptionally high incidence of SAH in Finland might have originated from reviews including old Finnish studies without the incidence rates standardized to reference populations, such as the European Standard Population. ${ }^{7-9)}$ The 3-year mean standardized incidence in Finland decreased from 11.7 in 1998-2000 to 8.9 per 100,000 persons in 2010-2012 together with decreasing smoking rates. ${ }^{10)}$ In contrast, the regional incidence rate of SAH in Japan was $15.4^{11)}-22.7^{8)}$ per 100,000, but the nationwide incidence rate and recent trends of incidence of SAH in Japan have never been reported.

Trends in the incidence of SAH worldwide before 2004 indicated either stable ${ }^{5,12-15)}$ or decreasing rates, ${ }^{16,17)}$ whereas either decrease ${ }^{10,18)}$ or increase ${ }^{19,20)}$ with regional variations was reported after 2005. The recent meta-analysis of worldwide incidence of aneurysmal SAH ${ }^{21)}$ between January 1960 and March 2017 suggested SAH incidence was associated with blood pressure and smoking prevalence. This meta-analysis included 75 studies from 32 countries with 8176 patients with SAH studied over $67,746,051$ person-years. Overall crude incidence of $\mathrm{SAH}$ across all midyears was 7.9 [95\% confidence interval (CI), 6.9-9.0] per 100,000 person-years; and the risk ratio (RR) was 1.3 for females (95\% CI, 0.98-1.7). Compared with males aged $45-54$ years, the RR was 2.5 in Japanese females older than 75 years (1.8-3.4) and 1.5 in European females older than 75 years (0.9-2.5). Clearly, elderly females in Japan have a greatly increased risk of SAH. Global incidence of SAH declined from 10.2 (8.4-12.5) in 1980 to $6.1(4.9-7.5)$ per 100,000 person-years in 2010 or by $1.7 \%(0.6-2.8)$ annually between 1955 and 2014. Incidences of SAH declined by $46.2 \%$ in Asia, $40.6 \%$ in Europe, and 14.0\% in North America, but increased by $59.1 \%$ in Japan between 1980 and 2010. The global incidence of SAH declined by $7.1 \%$ (5.8-8.4) per mmHg decrease in systolic blood pressure and by $2.4 \%$ (1.6-3.3) per percent decrease in smoking prevalence. Worldwide incidence of SAH and decreases showed great regional differences, parallelly

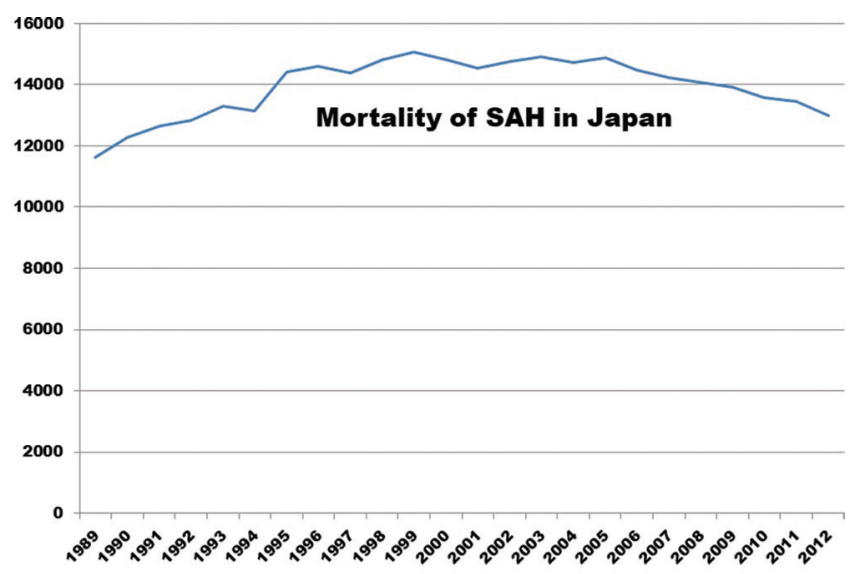

Fig. 1 Annual trend of mortality of subarachnoid hemorrhage (SAH) from 1989 to 2012 from records in a database at the Ministry of Health, Labour, and Welfare. Modified with permission from the Chugai-Igakusha. ${ }^{22}$

with decreases in blood pressure and smoking prevalence. Therefore, the incidence of SAH could be reduced by identifying the determinants for regional differences and further reducing blood pressure and smoking prevalence. However, all available Japanese data is regional, not nationwide, and extends only up to 2008. Figure 1 shows the mortality trend of SAH in Japan from records in a database at the Ministry of Health, Labour, and Welfare, ${ }^{22)}$ indicating the slight decline trend from 2004. However, we must recognize that the crude mortality of SAH could be changed based on the crude incidence of SAH, demographic change, aging change, change of mortality rate, and other related factors during the same period. Therefore, the recent trend in the nationwide incidence of SAH should be evaluated.

\section{Treatment for Aneurysmal SAH}

Meta-analysis of patients with aneurysmal SAH reported that endovascular coiling could achieve better clinical outcome than surgical clipping. ${ }^{23,24)}$ The American Heart Association/American Stroke Association guidelines indicated that endovascular coiling should be considered for patients with ruptured aneurysms suitable for both treatments (Class I; Level of Evidence B) ${ }^{25)}$ according to the randomized controlled trial (RCT) of the international subarachnoid aneurysm trial which demonstrated poor outcomes for surgical clipping compared with endovascular coiling. ${ }^{26)}$ However, no reliable clinical RCT is available that can be used directly to guide treatment in patients with poor clinical grading condition after aneurismal SAH. ${ }^{27)}$

Recent meta-analysis found that the outcomes with endovascular coiling was not superior to surgical 
clipping in patients with high-grade aneurysmal SAH, and that coiling carried greater risk of mortality. ${ }^{28)}$ Analysis of the Japanese Stroke Databank found no significant difference in poor outcome of modified Rankin Scale (mRS) >2 between surgical clipping and endovascular coiling even at discharge. ${ }^{29}$ A Japanese nationwide study in 2012 reported that surgical clipping was associated with lower in-hospital mortality compared with endovascular coiling. ${ }^{30)}$ Therefore, the indications for the treatment method tend to depend on the protocol in each institute. The ruptured aneurysm wall might be more fragile due to genetic factors in Japanese compared with western people, because UCA was 2.8 times more likely to rupture in Japanese than in western population, ${ }^{31)}$ and Asian people was a significant risk factor for rupture during the procedure of endovascular coiling $(P<0.0001){ }^{32)}$

The outcome at discharge measured by mRS was evaluated by use of the comprehensive national database in Japan. ${ }^{33)}$ In this database registered between 2010 and 2015, propensity score-matched analysis was conducted for aneurysmal SAH. Poor outcome of $\mathrm{mRS}>2$ showed no significant difference between endovascular coiling and surgical clipping ( $48.3 \%$ vs $47.7 \%, P=0.48$ ). However, significantly lower in-hospital mortality after surgical clipping was observed compared with endovascular coiling (7.1\% vs $12.2 \%, P<0.001)$. This study conducted additional meta-analysis of studies using the nationwide databases comparing between surgical clipping and endovascular coiling published from 2007 to 2018. No significant association was found for poor outcome at discharge between endovascular coiling and surgical clipping [odds ratio (OR), 1.08; 95\% CI, 0.93-1.26; $P=0.31$ ] (Fig. 2). Lower in-hospital mortality was found after surgical clipping than after endovascular coiling, but without significant difference (0.74; 0.52-1.04; $P=0.08$ ) (Fig. 3). This meta-analysis was mainly based on the data from nationwide databases in Japan. The reason for no significant difference in poor outcomes might be due to the lower chance for positive life-saving treatment and higher indication for withdrawal in elderly patients, because endovascular coiling is easy to select for the elderly, and Japan has highest aging population in the world.

These data could tell us the different result of outcome for aneurysmal SAH in Japan from other countries. Therefore, possible speculations for this reason should be considered. The OECD data showed that Japan had the most acute care beds per 1000 population and the largest number of CT and magnetic resonance imaging (MRI) units per million population. ${ }^{3)}$ Consequently, neurosurgical facilities, neurosurgeons, and board-certified neurosurgeons can establish the diagnosis more rapidly and immediately treat all patients under universal health care system.

\section{Small UCA}

Asymptomatic UCAs are frequently discovered at screening check-ups in Japan. ${ }^{34)}$ Most such UCAs are small with diameter under $5 \mathrm{~mm} \cdot{ }^{35,36)}$ On the other hand, reported rates of small ruptured cerebral aneurysms of $\leq 5 \mathrm{~mm}$ and $<5 \mathrm{~mm}$ were over $45 \%{ }^{37,38)}$ and $35 \%,{ }^{39)}$ respectively. The reason for this discrepancy may be that most acute $\mathrm{SAH}$ originates from recently formed aneurysms, so called the small unruptured aneurysm verification (SUAVe) Study type I aneurysm. ${ }^{40,41)}$ Namely, this type I of UCA will rupture immediately after forming and may be difficult to follow clinically and radiologically from formation to rupture. However, this hypothesis

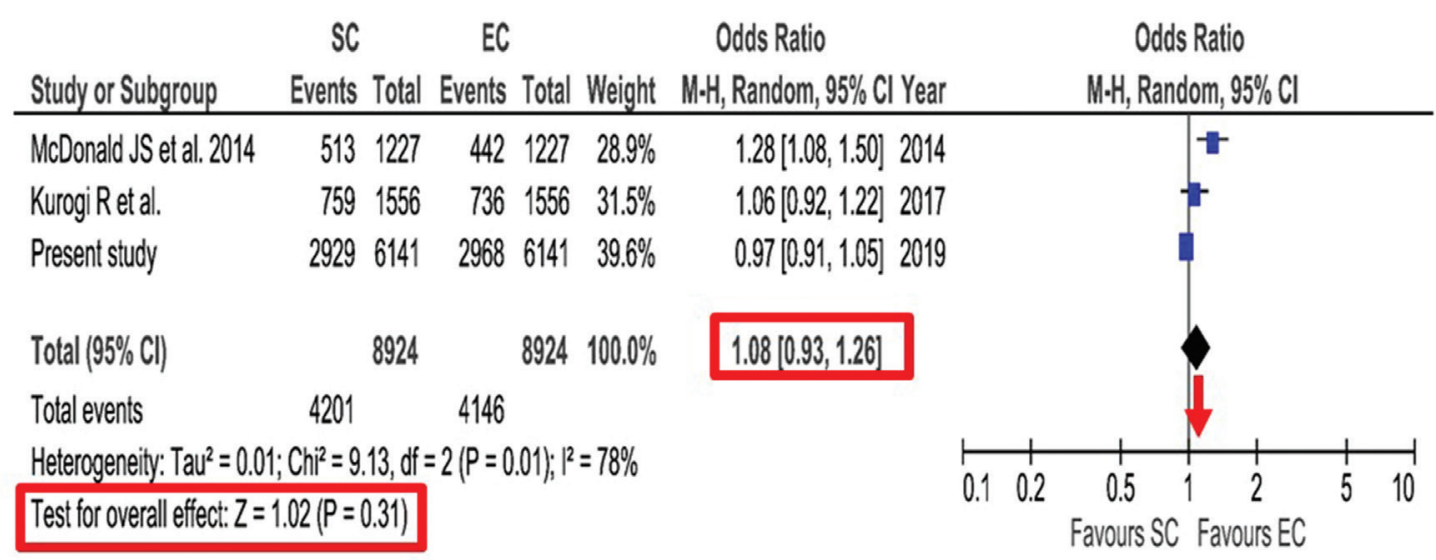

Fig. 2 Forest plot and meta-analysis of propensity score-matched poor outcome at discharge after aneurysmal subarachnoid hemorrhage. Modified with permission from Neurosurgical Review. ${ }^{33)}$ CI: confidence interval, EC: endovascular coiling, M-H: Mantel-Haenszel method, SC: surgical clipping. 


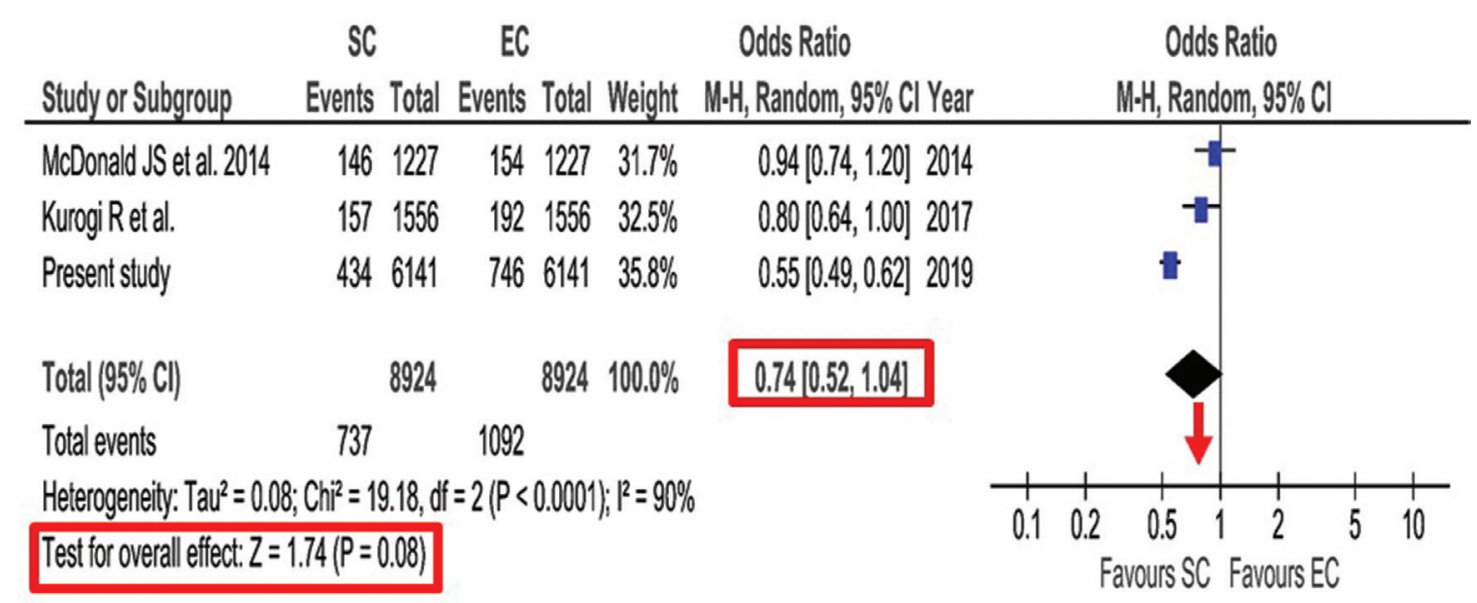

Fig. 3 Forest plot and meta-analysis of propensity score-matched in-hospital mortality after aneurysmal subarachnoid hemorrhage. Modified with permission from Neurosurgical Review. ${ }^{33)}$ CI: confidence interval, EC: endovascular coiling, M-H: Mantel-Haenszel method, SC: surgical clipping.

remains unproven. Therefore, more knowledge is needed about the natural history and management for small UCAs, although size is one of the risk factors for rupture. ${ }^{35)}$

Two prospective cohort studies have investigated small UCA in Japan ${ }^{40)}$ and Germany. ${ }^{42)}$ The criteria for small UCA were $5 \mathrm{~mm}$ in Japan and $7 \mathrm{~mm}$ in Germany, but the final annual rupture rates were 2.7 times higher in Japan at $0.54 \%$ per year compared with Germany at $0.2 \%$ per year, similar to the findings of the PHASES study. ${ }^{31)}$ Interestingly, the risk factors were similar in both studies, which identified age $<50$ years and hypertension. Moreover, age $<50$ years was another risk factor with special reference to small UCAs, ${ }^{40,42,43)}$ despite age over 70 years old as the reported risk factor for rupture for all UCAs. ${ }^{31,44)}$ The risk of aneurysm rupture is higher in the Japanese population than in other populations, despite the similar prevalence of UCA in these populations. ${ }^{45)}$ Therefore, genetic differences might be an explanation for the higher rupture rates in the SUAVe Study and in the UCA Study of Japan (UCAS Japan). However, the incidence of SAH in China is not high, indicating that any genetic influence may not be so important. ${ }^{46)}$

Recently, we investigated the rupture risk for small UCA using the data of UCAS Japan. ${ }^{47)}$ During registration, 2839 patients $(49.6 \%)$ had 3132 (46.8\%) small UCAs of 3-4 $\mathrm{mm}$ in diameter. We investigated the registered, treated, and rupture numbers of these small UCAs and the annual rupture rate, and compared the characteristics of patients and aneurysms to those of larger unruptured aneurysms $(\geq 5 \mathrm{~mm}$ ) to identify the risk factors using univariate and multivariate analyses. Treatment of small UCAs was performed in 1132 (37.1\% of all treated aneurysms) patients and rupture occurred in $23(20.7 \%$ of all ruptured aneurysms) patients (Fig. 4). If all small UCAs $<5 \mathrm{~mm}$ were followed up without interventional treatment, the proportion of small ruptured UCA was estimated at $32.4 \%$ of all ruptured aneurysms. Therefore, the annual rupture rate of small aneurysms is low, but the actual number of ruptures is not low. Consequently, small aneurysms that rupture during the follow-up period could be detected, screened, and managed based on the individual risk factors. Additionally, multivariate risk-factor analysis revealed that brain check-up screening [hazard ratio (HR), 4.1; 95\% CI, 1.2-14.4], history of SAH $(10.8 ; 2.3-51.1)$, uncontrolled hypertension $(5.2 ; 1.8-15.3)$, and location on the anterior communicating artery $(5.0 ; 1.6-15.5)$ were independent predictors of rupture. However, the log-rank test found no significant association with brain check-up screening $(P=0.16)$ (Fig. 5). Possible selection criteria for treatment of patients with small UCAs include history of SAH, uncontrolled hypertension, location on the anterior communicating artery, and young age.

\section{Treatment for UCA}

The American Heart Association and the American Stroke Association updated the guidelines for managing patients with UCAs in $2015,{ }^{48)}$ indicating that the treatment risk for patients with UCAs is related to advancing age, medical comorbidities, and aneurysm location and size, so observation is a reasonable alternative in older patients ( $>65$ years of age) and patients with small asymptomatic UCAs associated with medical comorbidities and low hemorrhage risk based on location, size, morphology, family 

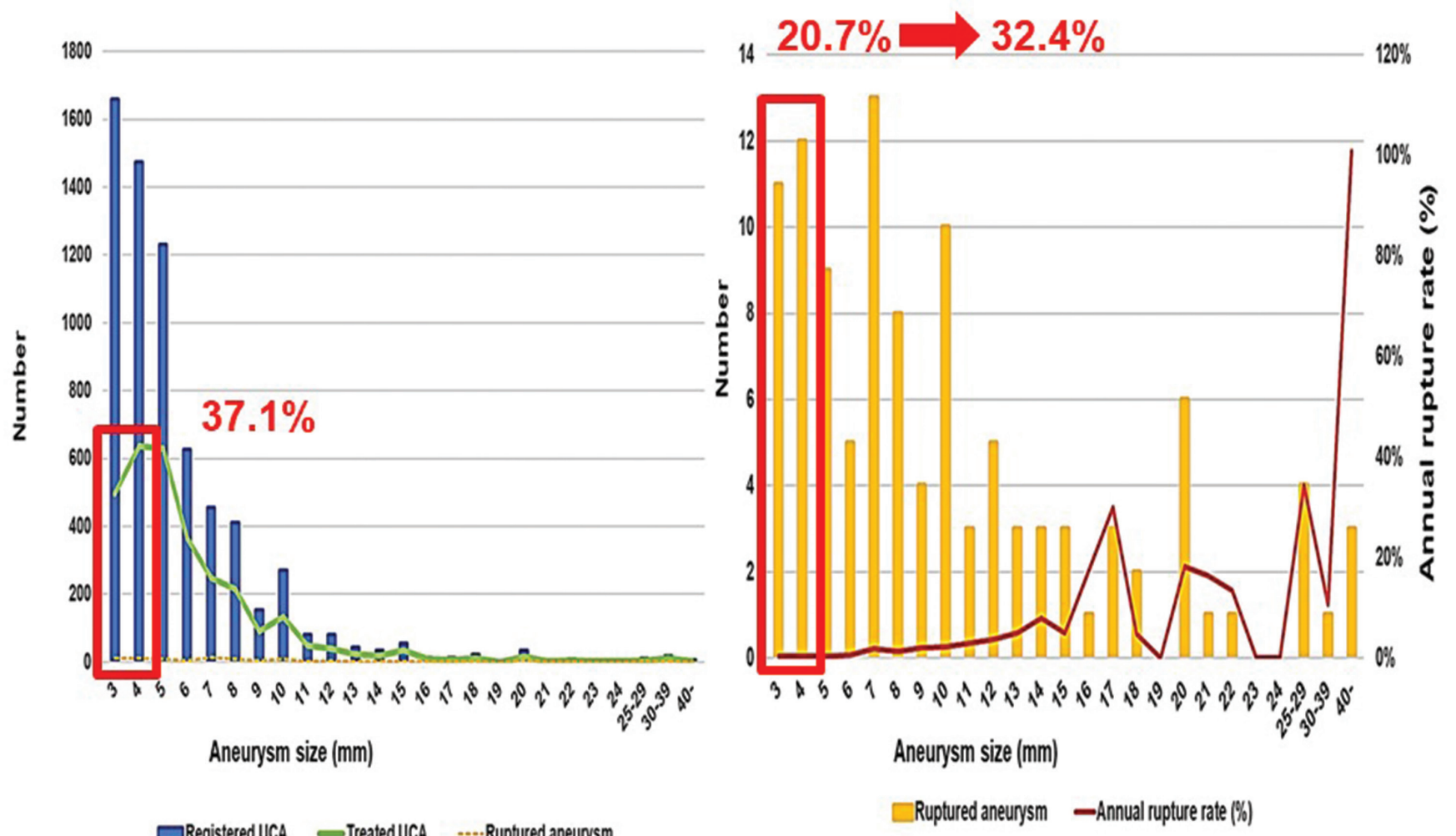

Fig. 4 Registered, treated, and rupture numbers of aneurysms, and annual rupture rate according to aneurysm size. Modified with permission from Journal of Neurosurgery. ${ }^{47)}$ UCA: unruptured cerebral aneurysm.

history, and other relevant factors (Class IIa; Level of Evidence B). Therefore, the treatment indications for UCA in the elderly remain unclear. Clearly, some elderly patients are indicated for interventional treatment based on the individual rupture risk, as the aged population increases worldwide. In fact, both surgical clipping and endovascular coiling were performed for UCA in increasing numbers of elderly per 100,000 Medicare beneficiaries from 2000 to $2010 .^{20)}$ Higher age is a significant risk factor for UCA rupture in elderly patients. ${ }^{49)}$ The Japanese population includes a very high proportion of elderly individuals and Japan has the highest life expectancy at birth worldwide, according to health data from the OECD. ${ }^{50)}$ Therefore, many elderly patients aged over 65 years old receive treatment for UCAs in Japan. Such aging of the population is expected to occur in other countries in the near future. Consequently, the outcome and risk factors for morbidity in elderly patients with UCAs should be investigated.

The recent meta-analysis ${ }^{2)}$ included 114 studies containing 106,433 patients with 108,263 UCAs. Endovascular treatment (74 studies) showed a pooled clinical complication risk of 4.96\% (95\% CI, 4.00-6.12) and case-fatality rate of $0.30 \%(0.20-0.40)$. Risk factors

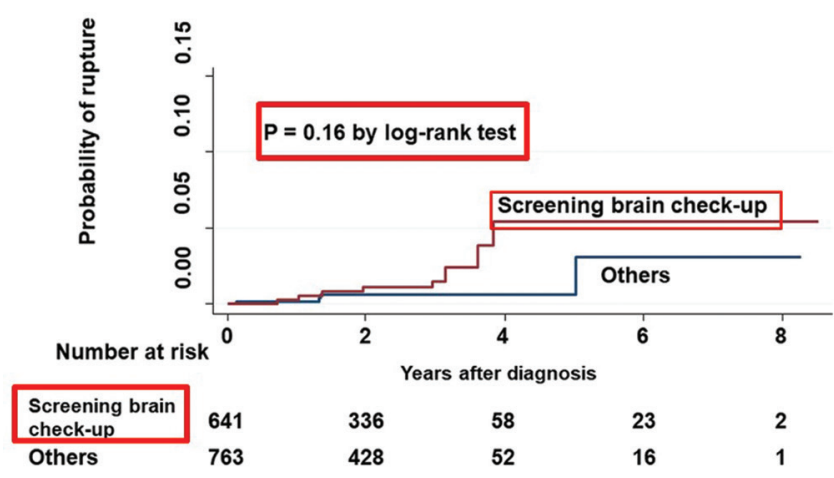

Fig. 5 Kaplan-Meier curve showing probability of rupture in patients with small unruptured cerebral aneurysms detected through brain check-up screening. Modified with permission from Journal of Neurosurgery. ${ }^{47}$

associated with complications were female (pooled OR, 1.06; 95\% CI, 1.01-1.11), cardiac comorbidity (2.27; 1.53-3.37), diabetes mellitus (OR, 1.81; 95\% CI, 1.05-3.13), hyperlipidemia (1.76; 1.3-2.37), wide aneurysm neck ( $>4 \mathrm{~mm}$ or dome-to-neck ratio $>1.5$ ) (1.71; 1.38-2.11), posterior circulation aneurysm (1.42; 1.15-1.74), stenting $(3.43 ; 1.45-8.09)$ and stent-assisted coiling $(1.82 ; 1.16-2.85)$. Neurosurgical treatment (54 studies) showed a pooled complication 
risk of $8.34 \%(6.25-11.10)$ and case-fatality rate of $0.10 \%(0-0.20)$. Risk factors associated with complications were age (OR per year increase, 1.02; 95\% CI, 1.01-1.02), female (0.43; 0.32-0.85), anticoagulation agents (6.36; 2.55-15.85), coagulopathy (2.14; 1.13-4.06), congestive heart failure (2.71; 1.57-4.69), diabetes mellitus $(2.38 ; 1.54-3.67)$, smoking (1.95; $1.36-2.79)$, hypertension $(1.45 ; 1.03-2.03)$, posterior aneurysm location $(7.25 ; 3.70-14.20)$, and aneurysm calcification $(2.89 ; 1.35-6.18)$.

The present study found $51 \%$ of endovascular treatments and $54 \%$ of neurosurgical treatments were from Asia, almost all from Japan, Korea, and China. The pooled crude risk of procedural clinical complications in regions found the risk for endovascular treatment in Asia was 3.31 (95\% CI, 2.46-4.44), about half that of other areas, and 3.34 (2.88-6.50) for neurosurgical treatment, about one fifth that of other areas. Therefore, such procedures are very safe in Asia, especially neurosurgical treatment, compared with other areas.

\section{Conclusion}

Cerebral aneurysm characteristics and environmental factors in Japan have unique features not found in other countries. Identification of these features is important for the understanding of cerebral aneurysms and SAH worldwide. International joint randomized controlled trials or real-world connected big database study with artificial intelligence may be necessary for further research.

\section{Acknowledgment}

This study was funded by a grant from the Japan Society for the Promotion of Science, Grant-in-Aid for Scientific Research (C) 17K10829.

\section{Contributors}

All authors have made substantial contributions to the intellectual content of the paper, have approved the final manuscript, and agree with submission to this journal. Fusao Ikawa is the corresponding author for this study and the principal investigator. He takes responsibility for data management, accuracy of statistical analysis, conduct of the research, and drafting of the manuscript.

\section{Conflicts of Interest Disclosure}

The authors report no conflicts of interest concerning the materials or methods used in this study or the findings specified in this paper. All authors have registered online Self-reported COI Disclosure Statement Forms through the website for JNS members.

\section{References}

1) Nieuwkamp DJ, Setz LE, Algra A, Linn FH, de Rooij NK, Rinkel GJ: Changes in case fatality of aneurysmal subarachnoid haemorrhage over time, according to age, sex, and region: a meta-analysis. Lancet Neurol 8: 635-642, 2009

2) Algra AM, Lindgren A, Vergouwen MDI, et al.: Procedural clinical complications, case-fatality risks, and risk factors in endovascular and neurosurgical treatment of unruptured intracranial aneurysms: a systematic review and meta-analysis. JAMA Neurol 76: 282-293, 2019

3) OECD data on Health, Health equipment. https://data. oecd.org/health.htm\#profile-Health\% 20equipment (Accessed on 2019 Feb 17)

4) Ingall T, Asplund K, Mähönen M, Bonita R: A multinational comparison of subarachnoid hemorrhage epidemiology in the WHO MONICA stroke study. Stroke 31: 1054-1061, 2000

5) Inagawa T: Trends in incidence and case fatality rates of aneurysmal subarachnoid hemorrhage in Izumo City, Japan, between 1980-1989 and 1990-1998. Stroke 32: 1499-1507, 2001

6) Korja M, Kaprio J: Controversies in epidemiology of intracranial aneurysms and SAH. Nat Rev Neurol 12: 50-55, 2016

7) Linn FH, Rinkel GJ, Algra A, van Gijn J: Incidence of subarachnoid hemorrhage: role of region, year, and rate of computed tomography: a meta-analysis. Stroke 27: 625-629, 1996

8) de Rooij NK, Linn FH, van der Plas JA, Algra A, Rinkel GJ: Incidence of subarachnoid haemorrhage: a systematic review with emphasis on region, age, gender and time trends. J Neurol Neurosurg Psychiatry 78: 1365-1372, 2007

9) van Gijn J, Kerr RS, Rinkel GJ: Subarachnoid haemorrhage. Lancet 369: 306-318, 2007

10) Korja M, Lehto $H$, Juvela $S$, Kaprio J: Incidence of subarachnoid hemorrhage is decreasing together with decreasing smoking rates. Neurology 87: 1118-1123, 2016

11) Takashima N, Arima $H$, Kita $Y$, et al.: Incidence, management and short-term outcome of stroke in a general population of 1.4 million Japanese -Shiga Stroke Registry. Circ J 81: 1636-1646, 2017

12) Ohkuma H, Fujita S, Suzuki S: Incidence of aneurysmal subarachnoid hemorrhage in Shimokita, Japan, from 1989 to 1998. Stroke 33: 195-199, 2002

13) Kozák N, Hayashi M: Trends in the incidence of subarachnoid hemorrhage in Akita Prefecture, Japan. J Neurosurg 106: 234-238, 2007

14) Sivenius J, Tuomilehto J, Immonen-Räihä P, et al.: Continuous 15-year decrease in incidence and mortality of stroke in Finland: the FINSTROKE study. Stroke 35: 420-425, 2004 
15) Rothwell PM, Coull AJ, Giles MF, et al.: Change in stroke incidence, mortality, case-fatality, severity, and risk factors in Oxfordshire, UK from 1981 to 2004 (Oxford Vascular Study). Lancet 363: 1925-1933, 2004

16) Truelsen T, Bonita R, Duncan J, Anderson NE, Mee E: Changes in subarachnoid hemorrhage mortality, incidence, and case fatality in New Zealand between 1981-1983 and 1991-1993. Stroke 29: 2298-2303, 1998

17) Koffijberg H, Buskens E, Granath F, et al.: Subarachnoid haemorrhage in Sweden 1987-2002: regional incidence and case fatality rates. $J$ Neurol Neurosurg Psychiatry 79: 294-299, 2008

18) Lindekleiv HM, Njølstad I, Ingebrigtsen T, Mathiesen EB: Incidence of aneurysmal subarachnoid hemorrhage in Norway, 1999-2007. Acta Neurol Scand 123: 34-40, 2011

19) Wong GK, Wun Tam YY, Zhu XL, Poon WS: Incidence and mortality of spontaneous subarachnoid hemorrhage in Hong Kong from 2002 to 2010: a Hong Kong hospital authority clinical management system database analysis. World Neurosurg 81: 552-556, 2014

20) Jalbert JJ, Isaacs AJ, Kamel H, Sedrakyan A: Clipping and coiling of unruptured intracranial aneurysms among Medicare beneficiaries, 2000 to 2010. Stroke 46: 2452-2457, 2015

21) Etminan N, Chang HS, Hackenberg K, et al.: Worldwide incidence of aneurysmal subarachnoid hemorrhage according to region, time period, blood pressure, and smoking prevalence in the population: a systematic review and meta-analysis. JAMA Neurol 76: 588-597, 2019

22) Ikawa F, Kato Y, Kobayashi S: [Epidemiology and statistical data of ruptured cerebral aneurysm in Japan]. In Ikawa F, Morita A, Kayama T (eds): [Unruptured Cerebral Aneurysm: Japan Standard], Chugai-Igakusha, Tokyo, 2015, pp. 10-18 (Japanese)

23) Li H, Pan R, Wang H, et al.: Clipping versus coiling for ruptured intracranial aneurysms: a systematic review and meta-analysis. Stroke 44: 29-37, 2013

24) Lanzino G, Murad MH, d'Urso PI, Rabinstein AA: Coil embolization versus clipping for ruptured intracranial aneurysms: a meta-analysis of prospective controlled published studies. AJNR Am J Neuroradiol 34: 1764-1768, 2013

25) Connolly ES, Rabinstein AA, Carhuapoma JR, et al.: Guidelines for the management of aneurysmal subarachnoid hemorrhage: a guideline for healthcare professionals from the American Heart Association/American Stroke Association. Stroke 43: 1711-1737, 2012

26) Molyneux A, Kerr R, Stratton I, et al.: International Subarachnoid Aneurysm Trial (ISAT) of neurosurgical clipping versus endovascular coiling in 2143 patients with ruptured intracranial aneurysms: a randomised trial. Lancet 360: 1267-1274, 2002

27) Lindgren A, Vergouwen MD, van der Schaaf I, et al.: Endovascular coiling versus neurosurgical clipping for people with aneurysmal subarachnoid haemorrhage. Cochrane Database Syst Rev 8: CD003085, 2018

28) Xia ZW, Liu XM, Wang JY, et al.: Coiling is not superior to clipping in patients with high-grade aneurysmal subarachnoid hemorrhage: systematic review and meta-analysis. World Neurosurg 98: 411-420, 2017

29) Ikawa F, Abiko M, Ishii D, et al.: Analysis of outcome at discharge after aneurysmal subarachnoid hemorrhage in Japan according to the Japanese stroke databank. Neurosurg Rev 41: 567-574, 2018

30) Kurogi R, Kada A, Nishimura K, et al.: Effect of treatment modality on in-hospital outcome in patients with subarachnoid hemorrhage: a nationwide study in Japan (J-ASPECT Study). J Neurosurg 128: 1318-1326, 2018

31) Greving JP, Wermer MJ, Brown RD, et al.: Development of the PHASES score for prediction of risk of rupture of intracranial aneurysms: a pooled analysis of six prospective cohort studies. Lancet Neurol 13: 59-66, 2014

32) Elijovich L, Higashida RT, Lawton MT, Duckwiler G, Giannotta S, Johnston SC: Predictors and outcomes of intraprocedural rupture in patients treated for ruptured intracranial aneurysms: the CARAT study. Stroke 39: 1501-1506, 2008

33) Ikawa F, Michihata N, Matsushige T, et al.: In-hospital mortality and poor outcome after surgical clipping and endovascular coiling for aneurysmal subarachnoid hemorrhage using nationwide databases: a systematic review and meta-analysis. Neurosurg Rev Epub 2019 Apr 2

34) Nakagawa T, Hashi K: The incidence and treatment of asymptomatic, unruptured cerebral aneurysms. J Neurosurg 80: 217-223, 1994

35) UCAS Japan Investigators, Morita A, Kirino T, Hashi K, et al.: The natural course of unruptured cerebral aneurysms in a Japanese cohort. $N$ Engl J Med 366: 2474-2482, 2012

36) Imaizumi Y, Mizutani T, Shimizu K, Sato Y, Taguchi J: Detection rates and sites of unruptured intracranial aneurysms according to sex and age: an analysis of MR angiography-based brain examinations of 4070 healthy Japanese adults. J Neurosurg 130: 573-578, 2018

37) Froelich JJ, Neilson S, Peters-Wilke J, et al.: Size and location of ruptured intracranial aneurysms: a 5-year clinical survey. World Neurosurg 91: 260-265, 2016

38) Lee GJ, Eom KS, Lee C, Kim DW, Kang SD: Rupture of very small intracranial aneurysms: incidence and clinical characteristics. J Cerebrovasc Endovasc Neurosurg 17: 217-222, 2015

39) Dolati P, Pittman D, Morrish WF, Wong J, Sutherland GR: The frequency of subarachnoid hemorrhage from very small cerebral aneurysms $(<5 \mathrm{~mm})$ : a population-based study. Cureus 7: e279, 2015

40) Sonobe M, Yamazaki T, Yonekura M, Kikuchi H: Small unruptured intracranial aneurysm verification study: SUAVe study, Japan. Stroke 41: 1969-1977, 2010 
41) Mitchell P, Jakubowski J: Estimate of the maximum time interval between formation of cerebral aneurysm and rupture. I Neurol Neurosurg Psychiatry 69: 760-767, 2000

42) Güresir E, Vatter H, Schuss P, et al.: Natural history of small unruptured anterior circulation aneurysms: a prospective cohort study. Stroke 44: 3027-3031, 2013

43) Nahed BV, DiLuna ML, Morgan T, et al.: Hypertension, age, and location predict rupture of small intracranial aneurysms. Neurosurgery 57: 676-683, 2005

44) Tominari S, Morita A, Ishibashi T, et al.: Prediction model for 3-year rupture risk of unruptured cerebral aneurysms in Japanese patients. Ann Neurol 77: 1050-1059, 2015

45) Vlak MH, Algra A, Brandenburg R, Rinkel GJ: Prevalence of unruptured intracranial aneurysms, with emphasis on sex, age, comorbidity, country, and time period: a systematic review and metaanalysis. Lancet Neurol 10: 626-636, 2011

46) Zhang J, Liu G, Arima H, et al.: Incidence and risks of subarachnoid hemorrhage in China. Stroke 44: 2891-2893, 2013
47) Ikawa F, Morita A, Tominari S, et al.: Rupture risk of small unruptured cerebral aneurysms. J Neurosurg Epub 2019 Jan 25

48) Thompson BG, Brown RD, Amin-Hanjani S, et al.: Guidelines for the management of patients with unruptured intracranial aneurysms: a guideline for healthcare professionals from the American Heart Association/American Stroke Association. Stroke 46: 2368-2400, 2015

49) Hishikawa T, Date I, Tokunaga K, et al.: Risk of rupture of unruptured cerebral aneurysms in elderly patients. Neurology 85: 1879-1885, 2015

50) OECD data on Health, Life expectancy at birth. https://data.oecd.org/healthstat/life-expectancy-atbirth.htm (Accessed on 2019 Mar 11)

Address reprint requests to: Fusao Ikawa, MD, PhD, Department of Neurosurgery, Shimane Prefectural Central Hospital, 4-1-1 Himebara, Izumo, Shimane 693-8555, Japan.

e-mail: fikawa-nsu@umin.ac.jp 